\title{
An Investigation on the Fatty Acid Content of Breast Milk from Mothers Residing in Low Socioeconomic Areas of Egypt
}

\author{
Laila Hussein ${ }^{1, *}$, Mahmoud. Ali Mohammad ${ }^{1,2}$, K. S. Kuhn³, Peter Furst ${ }^{3}$ \\ ${ }^{1}$ Department of Nutrition, National Research Center, Egypt \\ ${ }^{2}$ Baylor College of Medicine, Pediatrics-Nutrition, 100 Bates Street, Houston TX77030, United States \\ ${ }^{3}$ Institute of Biological Chemistry Nutrition, University of Hohenheim (140), Germany
}

Received November 23, 2019; Revised March 27, 2020; Accepted April 19, 2020

Copyright $\bigcirc 2020$ by authors, all rights reserved. Authors agree that this article remains permanently open access under the terms of the Creative Commons Attribution License 4.0 International License

\begin{abstract}
The study was carried on a small sample size of lactating Egyptian mothers from Urban Giza, who gave birth either to full-term or preterm babies. Mature milk was collected manually and was subjected to fatty acid analysis by gas chromatographic technique and the results were expressed as \% concentration of total FAs. The results showed the wide mean ratio (30:1) of the essential FA linoleic $(16.27 \%)$ to alphalinolenic ( $\alpha$-ALA) $(0.5 \%)$ acid concentrations, which exceeds the respective worldwide average (WWA) of $0.32 \%$. Conclusion: The milks of Egyptian lactating mothers, the only nutrient supply of breast infants is deficient in its DHA. This deficiency may have future adverse effects on learning and scholastic performances. A national strategy is urgently warranted for supplementing pregnant and lactating women with oily fish rich in DHA content to achieve the target 2 of the sustainable development goal2030.
\end{abstract}

Keywords Lactating Women, Mature Milk, Fullterm Babies, Preterm Babies, Fatty Acid Concentrations, Linoleic Acid, Linolenic Acid, Docosahexanoic Acid, Dietary Docosahexnoic Acid

\section{Introduction}

Human milk is considered "the gold standard" and the ideal food for both full-term and preterm infants for the first six months of post-natal life [1] conferring health benefits in the short and long terms $[2,3]$. Human milk lipid $(3-4 \mathrm{~g} / 100 \mathrm{~g})$ contributes to 40 to $55 \%$ of the total energy content and approximately $98 \%$ of this lipid is in the form of triglycerides (TG) $[4,5]$. Milk TGs contain saturated (SFA), mono-unsaturated (MUFA) and polyunsaturated fatty acids (PUFA) [6]. PUFA belongs either to the omega $-6(\omega 6)$ family represented by linoleic

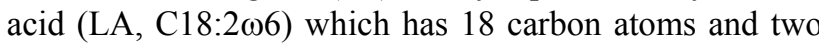
double bonds; the first double bond is located at the $6^{\text {th }}$ carbon atom $(\omega 6)$ from the methyl end of the chain. The omega- $3(\omega 3)$ family represented by alpha linolenic acid (ALA, C18:3 $\omega 3$ ) has also 18 carbon atoms and 3 double bonds; the first double bond is located at the $3^{\text {rd }}$ carbon atom $(\omega 3)$ from the methyl end of the chain [6] [Figure 1]. The essentiality of the FAs LA and ALA were recognized since the 1990s [7-10] and later docosahexaenoic acid (DHA, C22:6ஸ3) [13, 19]. LCPUFA with C20 such as arachidonic acid (AA) and C22 carbon atoms such as DHA are the main constituents of the structural membrane phospholipids in brain nerve tissue and the developed eye retina of infants $[11,12]$ but beneficial effects on preterm infants is most [13]. Approximately $11.1 \%$ of births worldwide and $12.0 \%$ of births in North America occur before the full gestational $(<37$ weeks gestation) period [14] and are called preterm babies and are high risk group resulting from unique biological suboptimal early exposures [15]. DHA, the most highly unsaturated long-chain $\Phi^{-3}$ FAs, influence the biophysical properties of membranes (e.g., fluidity, thickness, and deformability) and is particularly effective at accommodating transitional changes associated with transmembrane protein activation [16] and has a large impact on different cellular biological processes [17].

Maternal DHA is transported across the placenta and accumulated in the embryo brain from $30 \mathrm{wk}$ of gestation at a rate of $45-65 \mathrm{mg}$ DHA / $\mathrm{kg}$ fetal weight $/ \mathrm{d}$ [18] reaching a total of $400 \mathrm{mg}$ DHA during the last trimester[19] . Brain DHA represents about 50\% the whole body stores suggesting selective DHA uptake by the blood-brain barrier and active transfer to brain cells [20]. In 
breast-fed infants, brain DHA stores regularly increased to approximately $905 \mathrm{mg}[21,22]$ and tripled during the first two years of breast-feeding $[20,23]$. The in utero DHA accretion takes place only in the full term embryo and preterm infants are at high risk of developing deficit in DHA [18]. The maternal Ф-3 PUFA dietary intake during pregnancy and lactation has direct effect on breast milk DHA concentration, which has implications on fetal and neonate brain DHA content [24]. Breast milk DHA has long lasting effect on cognitive performance in adolescence according to PISA test scores for mathematics, reading, and science [25], while high milk concentration of linoleic acid correlated negatively with the above mentioned PISA scores [25]. The possible interpretation was based on the metabolic pathways of LA which decreased brain DHA by competitive interference with conversion of $\omega-3$ FA into DHA, competition for inclusion in brain phospholipids between DHA and LA's elongation product, $\omega-6$ docosapentaenoic acid (DPA6) which displace DHA in brain phospholipids [25]. Increasing intake of ALA, the plant-based precursor to DHA, does not significantly increase breast milk DHA levels [28].

The increased consumption of $₫-6$ PUFA during the last
60 years to replace saturated fat led to an imbalance in the breast milk $₫-6 / \infty-3$ ratio resulting in unfavorable effect on LCPUFA $\infty$-3 family; eicosapentaenoic acid (EPA, 20:5 $₫-3$ ) and DHA. Based on meta-analysis study on 65 worldwide reports on 2474 lactating women, human milk DHA concentration of $0.32 \pm 0.22 \mathrm{wt} \%$ and AA of $0.47 \pm$ $0.13 \mathrm{wt} \%$ were accepted today as the world wide average (WWA) [29]. Breast fed infants rely on breast milk as the sole source of nutrient supply to meet their omega - 3 FA requirement [30]. Presently, the adequate intake (AI) of DHA for pregnant and lactating women is $300 \mathrm{mg} /$ day DHA [31] so that 2 servings $(200-300 \mathrm{~g})$ of fish per week provide $3 \mathrm{~g}$ DHA weekly equivalent to $300 \mathrm{mg}$ daily [32-37].

In Egypt, there is scarce data on milk LCPUFA in healthy lactating mothers and the single report dated back to 1986 [38]. Substantial new evidence has emerged warrant reassessment of the data [29]. The aim of the present study is to fill a gap in knowledge and present the FA composition of human mature milk collected from lactating women delivering full-term and preterm infants.

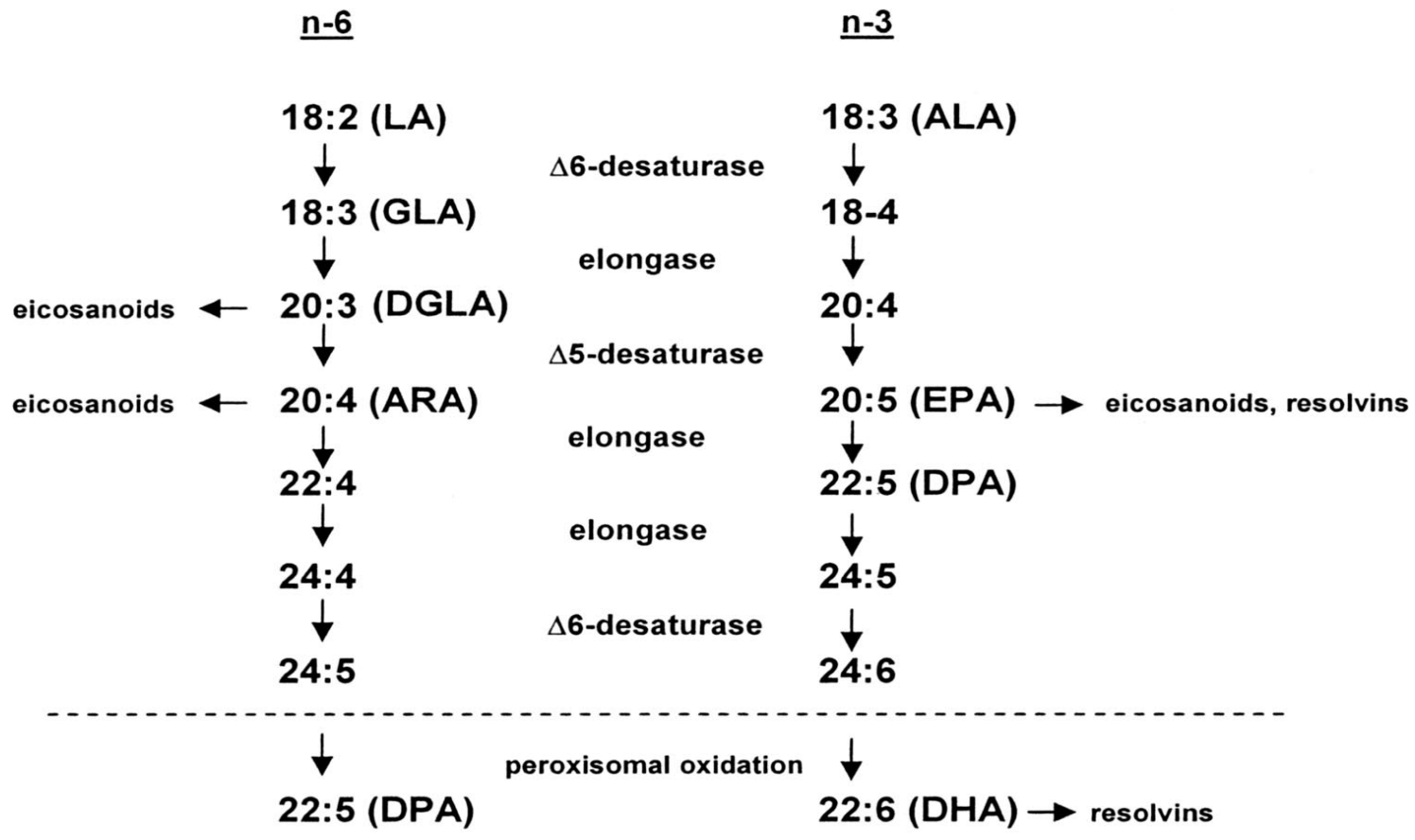

Figure 1. Biochemical pathway for the interconversion of $₫-6$ and $₫-3$ fatty acids. ALA, $\alpha$-linolenic acid; ARA, arachidonic acid; DGLA, dihomo- $\gamma$-linolenic acid; DHA, docosahexaenoic acid; DPA, docosapentaenoic acid; EPA, eicosapentaenoic acid; GLA, $\gamma$-linolenic acid; LA, linoleic acid. From Brenna [34] 


\section{Materials and Methods Study Design}

The mothers were recruited from Boulak El Dakrour public hospital - Giza, which serves patients from low socioeconomic communities. The study consisted of 25 non-smoking lactating mothers with mean age of $25.0 \pm 1.35(18-35 \mathrm{y})$, who gave birth to singleton 18 full term (birth weights $2.5-4 \mathrm{~kg}$ ) between the $38-40^{\text {th }}$ week of gestation and 7 preterm babies (birth weights $1.5-2.6 \mathrm{~kg}$ ) delivered between the $28^{\text {th }}-36^{\text {th }}$ week of gestation after uncomplicated premature rupture of the membranes. None was taking any medication and exclusion criteria including mothers younger than 16 years or older than 40 years; high risk pregnancies, abnormalities in lipid metabolism or absorption disorders, regular intake of fish oil supplements or chronic use of steroid or other related medications. Women accepted to donate their milks provided written or oral informed consent. Approval was obtained from the Human Research Ethics Committee of the hospital Boulak ElDakrour public hospital, which complied with the revised Helsinki Declaration (2004). After delivery all lactating mothers breast- fed their newborns and mature milk was collected in the subjects' own homes at pre-arranged times during the $2^{\text {nd }}-16^{\text {th }}$ week of lactation age (median value $=6$ weeks). The mothers were instructed to express a minimum of $3 \mathrm{ml}$ breast milk manually into sterile vials and the choice of feed for breast milk collection was left to the mothers' discretion because the FA composition of human milk had been reported to remain without any diurnal variation $2-4 \mathrm{~h}$ after the last feeding $[11,39]$. The milk samples were kept in a cool-box during transportation to the laboratory, where they were stored at $-20^{\circ} \mathrm{C}$ for subsequent $\mathrm{FA}$ analysis.

\section{Personal Data}

Information was collected on personal data and anthropometric measurements of the newborn and the breast fed infants were recorded according to standard methods.

\section{Assessment of Maternal Dietary Intake}

All mothers were consuming typical local omnivorous diets. Food consumed was recorded by the $24 \mathrm{~h}$ dietary recall according to standard protocols. The mother's usual food pattern of $₫-3$ FA containing foods was also assessed using a validated semiquantitative food frequency questionnaire. Questions regarding the consumption and servings sizes of various fish, shellfish, dairy products, eggs, chicken, or other meats on a monthly and/or weekly basis were recorded. Local species of fish and seafood recipes (including fresh, canned, smoked, salty) and method of preparation of food (e.g. broiled, roasted, fried, etc), brand name of the major source of edible fats and oils used for the preparation of the meals were included in the questionnaire to develop a locally appropriate food frequency questionnaire. All food records and food frequency questionnaires were manually checked and coded to maintain consistent data analysis. The quantity of fat and food LA, ALA, AA, EPA and DHA values were determined using our food FA database [40] unless otherwise indicated. The trans FA (TFA) was also calculated from the same data base. Based on the food item and its respective essential fatty acid content, combined with the usual equivalent weights of the portion, the amounts of the total omega 3 and omega- 6 fatty acids per gram or per portion size commonly consumed had been computed. According to the frequency of consumption, a rapid calculator of approximate dietary LA, ALA, AA and DHA intakes was developed and compared to the acceptable adequate intakes (AI)

\section{Analysis of Milk Fatty Acids}

All chemicals were obtained from Merck (Darmstadt, Germany] and all solvents contained butylhydroxytoluene (BHT) at a concentration of $50 \mathrm{mg} / \mathrm{l}$. Milk lipids were extracted from acidified aliquots $(0.5 \mathrm{ml})$ to recover any free FA generated by lipase activity at room temperature with chloroform-methanol mixture at a ratio of $1: 1 \mathrm{vol} / \mathrm{vol}$ [41]. The Tritridecanoin $\left(\mathrm{C}_{42} \mathrm{H}_{80} \mathrm{O}_{6}\right)$ served as the triglyceride internal standard solution $(5.0 \mathrm{mg} / \mathrm{ml}$ in $\mathrm{CHCl3}$ ) and was stable up to 1 month in freezer in a well-sealed amber bottle. An aliquot $(300 \mathrm{~mL})$ was added to reaction vial and evaporated to dryness with nitrogen. Following centrifugation (3000 rpm for $20 \mathrm{~min}$ ), the chloroform phase was aspirated and evaporated to dryness under a gentle stream of nitrogen. Transesterification was completed by incubating an aliquot $(10 \mathrm{mg})$ of the extracted lipid for $1 \mathrm{~h}$ at $100^{\circ} \mathrm{C}$ with a mixture of methanol: hexane $(4: 1)$ containing acetylchloride [42]. FA methyl esters (FAME) were prepared with BF3/ methanol (14\% $w t / v o l)$ and extracted into hexane (15). Analyses were performed with a Hewlett Packard 5890 gas chromatograph equipped with a flame ionization detector (Little Falls, DE). The column was a 30-m capillary (0.32 $\mathrm{mm}$ i.d.) Omega wax (Supelco, Bellefonte,PA). Chromatographic conditions were isothermal, Optimized injection, oven, and detection temperatures were carried out according to instructions of the manufacturer. Injection and detection temperatures were both set at $220^{\circ} \mathrm{C}$ and oven temperature was programmed to vary $5^{\circ} \mathrm{C} / \mathrm{min}$ from 40 to $225^{\circ} \mathrm{C}$. The carrier gas was hydrogen with a linear velocity of $45 \mathrm{~cm} / \mathrm{s}$ and a 1:60 split ratio. The FAME were identified by their retention time and were quantified by the amount of internal standard recovered and by comparison with authentic lipid standards (Sigma, Deisenhofen, Germany). The FA concentrations were expressed as specific FAs (\% weight/ total identified FA in milk lipid. FA were identified by equivalent chain length as determined using retention times generated by reference 
mixes of FAME. Detector response factors were calculated using quantitative reference mixes of FAME (Nu Chek Prep, Elysian, MN).

\section{Statistical analysis}

Descriptive statistics were reported using frequencies and percentages. Milk FA wt $\%$ of lactating mothers with term and preterm deliveries were presented as Whisker box plots showing median and interquartile ranges, means and standard errors. T-tests and Chi square tests were used to study the differences in mean values and Pearson correlation coefficients between lactational duration and milk FAs concentrations were computed with $\mathrm{P}<0.05$ as the significant level. The sum of all $\infty-6$ and $₫-3$ LCPUFA, and ratios from selected FAs were computed and presented [43]. All statistical analyses were conducted using the Excel software program.

\section{Results}

Characteristics of the lactating women and their breast fed infants are presented in Table 1. It can be seen that the mean gestation age of the preterm births was 33 months and their birth weight averaged $2.2 \mathrm{~kg}$. The average daily growth velocity of $29.4 \pm 3.37$ grams of the exclusive breast fed preterm infants is acceptable, though still significantly lower than their age matched full term babies $(\mathrm{P}<0.01)$. The proportion of preterm births $(41 \%)$ were significantly higher among women with body mass index $<19 \mathrm{~kg} / \mathrm{m}^{2}$ (Figure 2) compared with mothers with higher BMI ( $\chi 2$ test, $\mathrm{P}<0.05)$. Similarly, the proportion of preterm births $(21 \%)$ was higher among mothers giving seven or more previous births compared with those, who had two previous births (11 \%), but the differences didn't attain statistical significance $(\chi 2$ test, $\mathrm{P}>0.05)$. Table 2 presents the average concentrations of $21 \mathrm{FA}$ with chain lengths between $\mathrm{C} 12$ and C24 in the milk of lactating mothers with full term and preterm babies. On an average, saturated FAs (SFA) made up $49.3 \%$ of the total FA; palmitic acid with an average of $24.2 \%(13.6$ - 32.9) was the major SFA. The sum of SFA with C12:0 through C18:0 remained quite constant throughout the first 16 weeks of lactation. Oleic acid averaged 28.8 wt \% (range 15.9 - 34.7) and was the dominating MUFA in the milks of mothers with term $(28.6 \%)$ and preterm infants $(29.5 \%)$. Figure 3 is Whisker plot box for selected milk FA concentrations in mothers with full - and preterm births.

Table 1. Characteristics of the lactating women and their breast-fed infants

\begin{tabular}{|c|c|c|c|}
\hline Parameter & Fullterm & Preterm & P \\
\hline Gestational age, weeks & $40 \pm 0$ & $33 \pm 1.1$ & \multicolumn{1}{c|}{$\mathrm{ns}$} \\
\hline Age, years & $25.2 \pm 0.32$ & $24.9 \pm 1.6$ & $<0.05$ \\
\hline BMI, kg/ m2 & $25.69 \pm 0.19$ & $24.43 \pm 0.82$ & $<0.05$ \\
\hline Cord blood hemoglobin, g/dl & $14.34 \pm 0.07$ & $13.1 \pm 0.39$ & $<0.05$ \\
\hline Infant age, months & $1.48 \pm 0.03$ & $0.83 \pm 0.23$ & $<0.01$ \\
\hline Infant weight, $\mathrm{kg}$ & $3.32 \pm 0.03$ & $2.21 \pm 0.20$ & $\mathrm{~ns}$ \\
\hline WAZ & $0.41 \pm 0.04$ & $-0.41 \pm 0.41$ & $\mathrm{~ns}$ \\
\hline HAZ & $0.78 \pm 0.06$ & $-0.42 \pm 0.83$ & $<0.05$ \\
\hline WHZ & $-0.31 \pm 0.05$ & $-1.14 \pm 0.36$ & $<0.05$ \\
\hline
\end{tabular}

Mean \pm SE, ns $=$ not statistically significant 




Body Mass Index

Figure 2. Histogram for the distribution of the body mass index of the lactating mothers and the proportion of their respective preterm births 
Table 2. Fatty acid composition of milk from lactating mothers with full- and preterm infants

\begin{tabular}{|c|c|c|c|c|c|c|c|}
\hline \multirow{2}{*}{ Fatty acid } & & \multicolumn{2}{|c|}{ Egyptians[Present study] } & \multicolumn{2}{|c|}{ Swiss* } & \multirow{2}{*}{$\frac{\text { USA }^{* *}}{\text { Full-term }}$} & \multirow{2}{*}{$\begin{array}{c}\text { Global } * * * \\
\text { Full-term }\end{array}$} \\
\hline & & Full-term & Pre-term & Full-term & Pre-term & & \\
\hline Caprylic acid & C8:0 & & & $0.22 \pm 0.06$ & $0.21 \pm 0.08$ & $0.29 \pm 0.02$ & $0.16-0.28$ \\
\hline Capric acid & C10:0 & & & $1.46 \pm 0.38$ & $1.48 \pm 0.047$ & $1.18 \pm 0.12$ & $1.46-2.35$ \\
\hline Lauric acid & C12:0 & $10.75 \pm 1.07$ & $8.44 \pm 1.13$ & $5.26 \pm 2.10$ & $5.91 \pm 2.44$ & $4.65 \pm 0.47$ & $4.24-6.15$ \\
\hline Myristic acid & C14:0 & $9.80 \pm 1.04$ & $9.18 \pm 0.81$ & $6.27 \pm 1.93$ & $7.36 \pm 2.9$ & $5.02 \pm 0.40$ & $3.61-6.80$ \\
\hline Myristoleic acid & C14:1 & & & & & & \\
\hline Palmitic acid & C16:0 & $23.29 \pm 0.99$ & $26.49 \pm 1.16$ & $23.29 \pm 3.31$ & $23.10 \pm 3.46$ & $18.29 \pm 0.93$ & $18.62-22.26$ \\
\hline Palmitoleic acid & C16:1 & $1.93 \pm 0.14$ & $2.30 \pm 0.24$ & $2.44 \pm 0.77$ & $2.17 \pm 0.82$ & $3.36 \pm 0.41$ & \\
\hline Stearic acid & C18:0 & $5.14 \pm 0.45$ & $5.12 \pm 0.39$ & $2.44 \pm 0.77$ & $7.03 \pm 2.06$ & $6.75 \pm 0.37$ & $5.77-6.77$ \\
\hline Oleic acid & C18:1n9c & $28.59 \pm 1.21$ & $29.46 \pm 1.06$ & $37.67 \pm 4.82$ & $35.22 \pm 5.16$ & $35.72 \pm 2.45$ & \\
\hline Linoleic acid & C18:2@6 & $17.32 \pm 0.94$ & $15.22 \pm 1.91$ & $9.35 \pm 2.90$ & $10.21 \pm 3.64$ & $18.43 \pm 1.24$ & \\
\hline$\gamma$-Linolenic acid & C18:3@6 & $0.13 \pm 0.01$ & $0.12 \pm 0.02$ & $0.10 \pm 0.06$ & $0.09 \pm 0.04$ & $0.11 \pm 0.02$ & \\
\hline$\alpha$-Linolenic acid & C18:3@3 & $0.57 \pm 0.05$ & $0.44 \pm 0.06$ & $0.74 \pm 0.30$ & $0.75 \pm 0.43$ & $0.89 \pm 0.06$ & \\
\hline Arachidic acid & C20:0 & $0.14 \pm 0.01$ & $0.14 \pm 0.01$ & $0.20 \pm 0.04$ & $0.20 \pm 0.07$ & $0.11 \pm 0.01$ & $0.13-0.20$ \\
\hline Eicosadienoic acid & C20:2 & $0.47 \pm 0.02$ & $0.59 \pm 0.05$ & $0.26 \pm 0.07$ & $0.29 \pm 0.12$ & $0.66 \pm 0.01$ & \\
\hline Dihomo- $\gamma$-linoleic acid & C20:3@6 & $0.45 \pm 0.03$ & $0.56 \pm 0.04$ & $0.38 \pm 0.13$ & $0.35 \pm 0.12$ & $0.92 \pm 0.01$ & \\
\hline Eicosatrienoic acid & $\mathrm{C} 20: 3 \oplus 3$ & & & & & & \\
\hline Arachidonic acid & C20:4の6 & $0.44 \pm 0.02$ & $0.69 \pm 0.10$ & $0.42 \pm 0.12$ & $0.40 \pm 0.12$ & $1.32 \pm 0.02$ & \\
\hline Eicosapentaenoic acid & $\mathrm{C} 20: 5 \oplus 3$ & $0.15 \pm 0.01$ & $0.15 \pm 0.02$ & $0.06 \pm 0.04$ & $0.06 \pm 0.04$ & $0.14 \pm 0.00$ & \\
\hline Behenic acid & C22:0 & $0.05 \pm 0.00$ & $0.03 \pm 0.01$ & & & $0.06 \pm 0.01$ & $0.06-0.09$ \\
\hline Docosahexaenoic acid & C22:6の-3 & $0.24 \pm 0.03$ & $0.22 \pm 0.02$ & $0.28 \pm 0.18$ & $0.27 \pm 0.06$ & $0.29 \pm 0.08$ & \\
\hline Lignoceric acid & C24:0 & $0.05 \pm 0.00$ & $0.06 \pm 0.02$ & $0.08 \pm 0.03$ & $0.08 \pm 0.04$ & $0.028 \pm 0.03$ & \\
\hline MCSFA & & 20.55 & 17.62 & 13.21 & 14.96 & 11.14 & \\
\hline LCSFA & & 28.62 & 31.78 & 25.93 & 30.34 & 25.21 & \\
\hline
\end{tabular}


Table 2 Continued

\begin{tabular}{|c|c|c|c|c|c|}
\hline MUFA & 30.52 & 31.76 & 40.11 & 37.39 & 39.08 \\
\hline PFUA & 19.77 & 17.99 & 11.59 & 12.42 & 22.77 \\
\hline DNL, Breast & 20.55 & 17.62 & 13.21 & 14.96 & 11.14 \\
\hline DLN, Liver & 59.09 & 63.51 & 66.04 & 67.73 & 64.23 \\
\hline $\mathrm{DNL}(\mathrm{C} 16 / \mathrm{C} 18: 3 \oplus 3)$ & 1.34 & 1.74 & 2.49 & 2.26 & 0.99 \\
\hline DNL(C16:1/ C18:3@3 ) & 0.11 & 0.15 & 0.26 & 0.21 & 0.18 \\
\hline $\operatorname{DNL}(\mathrm{C} 16: 1 / \mathrm{C} 18: 3 \oplus 3)$ & 1.65 & 1.94 & 4.03 & 3.45 & 1.94 \\
\hline $\mathrm{SCD}(\mathrm{C} 16: 1 / \mathrm{C} 16: 0)$ & 0.08 & 0.09 & 0.10 & 0.09 & 0.18 \\
\hline $\operatorname{SCD}(\mathrm{C} 18: 1 / \mathrm{C} 18: 0)$ & 5.56 & 5.75 & 15.44 & 5.01 & 5.29 \\
\hline FADS1(C20:4の6 /C20:3@6) & 0.98 & 1.23 & 1.11 & 1.14 & 1.44 \\
\hline FADS2(C20:3@6 /C18:2@6) & 0.03 & 0.04 & 0.04 & 0.03 & 0.05 \\
\hline FADS2(C22:6@3/C20:5@3) & 1.60 & 1.47 & 4.67 & 4.50 & 2.00 \\
\hline
\end{tabular}

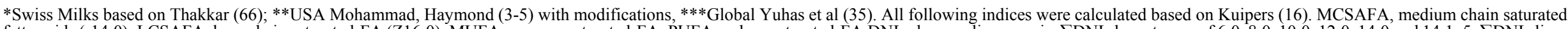

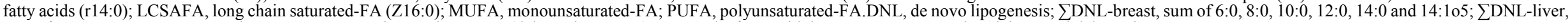
sum of 16:0, 16:1, 18:1, 20:1, and 22:1. SCD, stearoyl-CoA desaturase (delta-9 desaturase); FADS1/2, fatty acid desaturase genes 1 and 2 (delta-5 and delta-6 desaturase enzymes). 

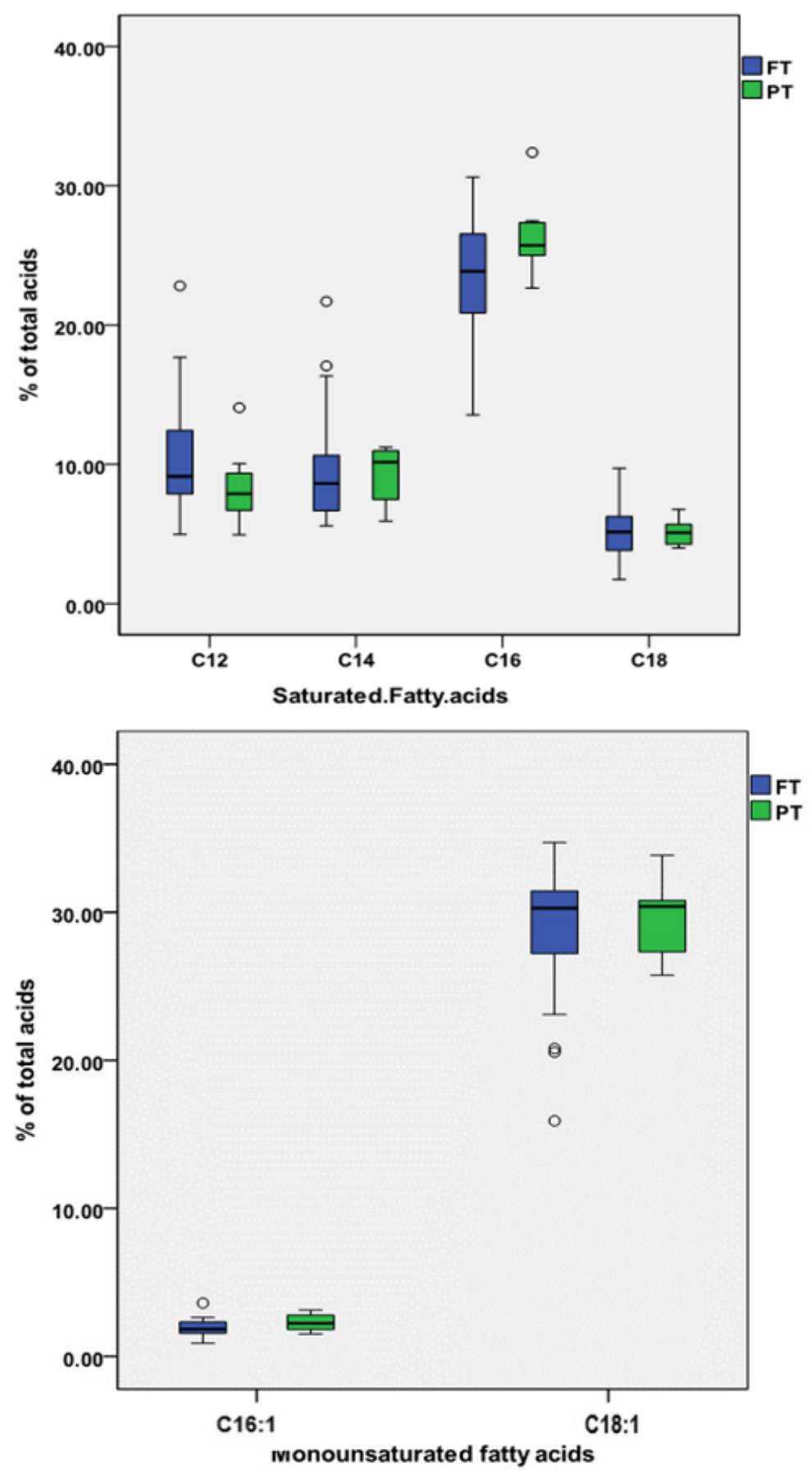

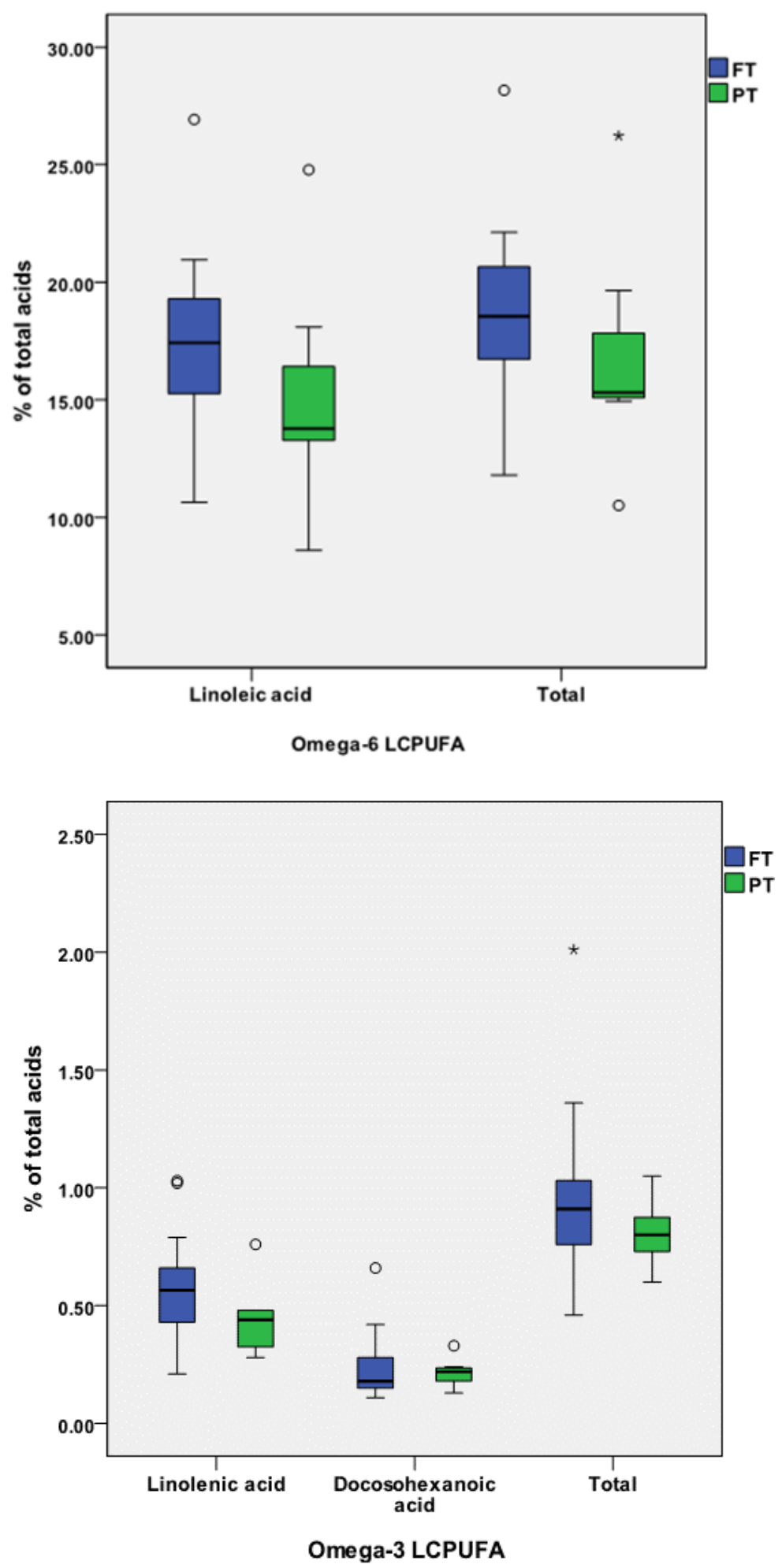

Figure 3. Whisker box plot for the milk fatty acid concentrations from lactating mothers delivering full term (FT) and preterm (PT) babies. Boxes show the median, 25 th and 75 th percentiles; the lower and upper adjacent hinges show the minimum and maximum values 
Milk LA averaged 16.7 wt \% (8.6 - 26.9 wt \%) representing 85.9 wt $\%$ of total PUFA. Low ALA concentrations of $0.57 \pm 0.05$ and $0.44 \pm 0.06$ wt \% were found in the milks of our lactating mothers with term and preterm babies, respectively. Disproportionate high LA/ ALA ratio of 30.4 and 34.6 were obtained in the milk of our lactating mothers with full term and preterm babies, respectively. In the present study, AA content was significantly higher $(\mathrm{P}<0.05)$ in milk of mothers from preterm babies $(0.69 \%)$ compared with term milk $(0.44 \%)$. DHA concentrations averaged 0.24 and $0.22 \mathrm{wt} \%$ in the milk of lactating mothers giving birth to term and preterm babies, respectively. The AA / DHA ratio averaged $1.8 \pm$ 0.67 and $3.1 \pm 2$ in the milks of our lactating mothers with term and preterm infants. The sum of the omega -3 LCPUFA EPA+ DHA accounted for 0.39 and $0.37 \mathrm{wt} \%$ in the milks of mothers with term and preterm infants; respectively compared with the respective recommended FAO ratios of 0.625 and 0.68 [31].

Table 3 presents the Pearson correlation coefficients between the progression of lactation (in weeks) and the concentration of 10 different milk FAs. Significant positive correlation coefficient of $\mathrm{r}=0.56(\mathrm{P}<0.01)$ was found between the progression of lactation in weeks and milk DHA concentration wt \%. This positive relation with DHA combined with prolonged breast-feeding are added value increasing the DHA supply to the nursing infant. Respective significant positive correlation coefficients of $r$ $=0.44(\mathrm{P}<0.05)$ and $\mathrm{r}=0.66(\mathrm{P}<0.01)$ were obtained for milk oleic and $\gamma \mathrm{LA}$ concentrations, respectively. However, progression of the lactation (in weeks) has negative effect on the concentration of the saturated fatty acids myristic (C14:0), palmitic (C16:0), stearic (C18:0) and lignoseric
(C24:0), as well as three other long chain monounsaturated

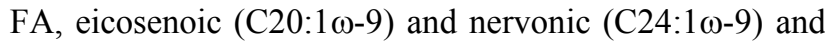
one diunsaturated LCFA: eicosadienoic (C20:2 $\omega-6)$

Table 3. Correlation Coefficients between the milk fatty acid concentration (\% FA) and the duration of lactation (weeks)

\begin{tabular}{|c|c|c|}
\hline Fatty acid & $\mathrm{r}$ & $\mathrm{P}$ \\
\hline Myristic (C14:0) & -0.41 & $<0.05$ \\
\hline Palmitic (C16:0) & -0.65 & $<0.01$ \\
\hline Stearic $(\mathrm{C} 18: 0)$ & -0.57 & $<0.01$ \\
\hline Lignoseric (C24:0) & -0.43 & $<0.05$ \\
\hline 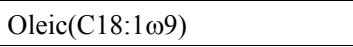 & 0.44 & $<0.05$ \\
\hline 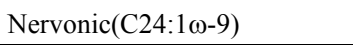 & -0.48 & $<0.05$ \\
\hline$\gamma$-Linolenic $(\mathrm{C} 18: 3 \omega-6)$ & 0.66 & $<0.01$ \\
\hline Eicosenoic $(\mathrm{C} 20: 1 \omega-9)$ & -0.40 & $<0.05$ \\
\hline Eicosadienoic $(\mathrm{C} 20: 2 \omega-6)$ & -0.70 & $<0.001$ \\
\hline Docosahexanoic ( $\mathrm{C} 22: 6 \omega-3)$ & 0.56 & $<0.01$ \\
\hline
\end{tabular}

The sum of the concentrations of the six intermediate metabolites (2.22 wt \%) which were gamma-linolenic acid $(\gamma \mathrm{LA})$ dihomo-gamma-linolenic acid (C20:3๑-6), eicosatrienoic acid (C20:3๑-3), AA (C20:4の-6) and docosohexanoic acid (C22:6ळ-3) in the milks collected from mothers giving birth preterm babies (Figure 4) were $38.8 \%$ higher $(\mathrm{P}<0.05)$ compared with the respective mean figure of $1.39 \mathrm{wt} \%$ obtained among those giving full term babies. Furthermore, milk DHA concentrations increased with the prolongation of lactation $(\mathrm{r}=0.56 ; \mathrm{P}<0.01)$, which could benefit the cognitive development of the Egyptian full-term and premature infants, where prolonged breast feeding is common practice among the majority of lactating women from low and medium socioeconomic classes.

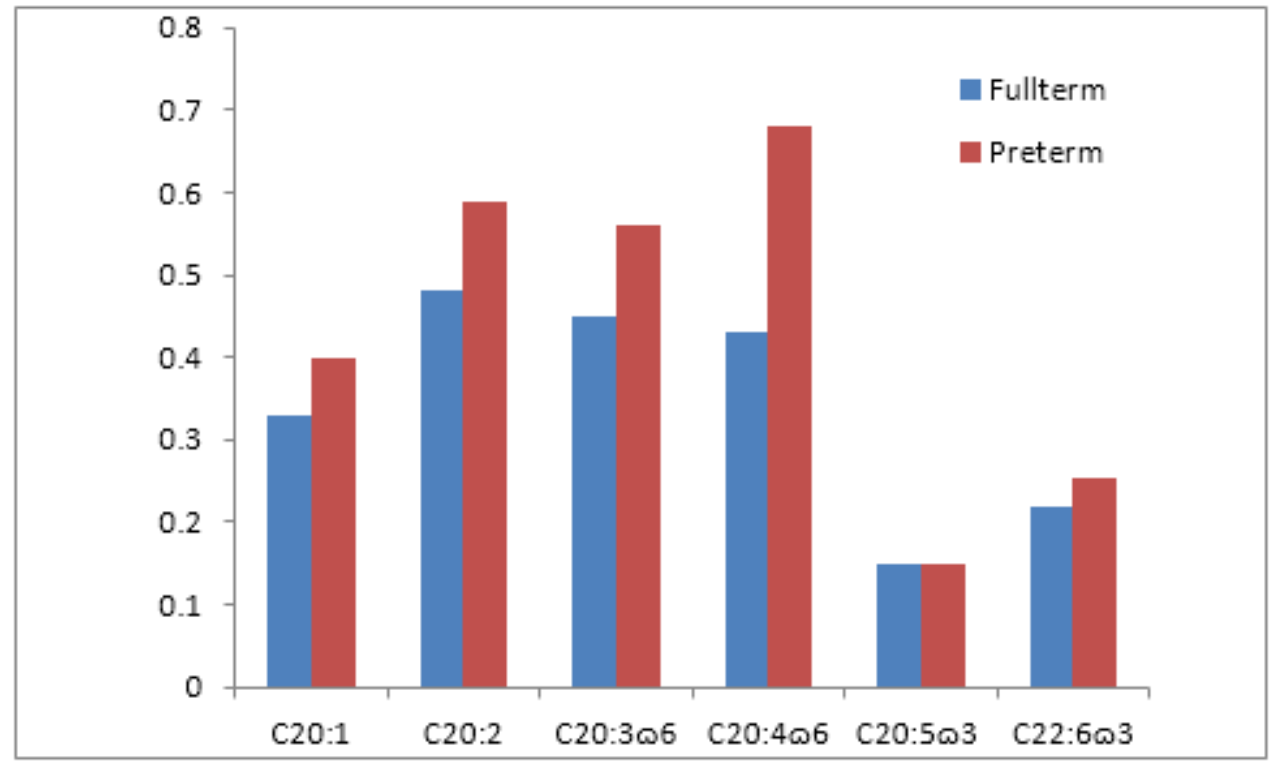

Milk long chain unsaturated fatty acids

Figure 4. Histogram for the concentration of six long chain unsaturated fatty acids (\% Fatty acids) in the breast milk from mothers with full term and preterm births 
Table 4. Semi quantitative food frequency questionnaire (FFQ) for estimating the usual intake of food sources rich in omega - 3 fatty acids.

\begin{tabular}{|c|c|c|c|c|c|c|c|c|c|c|c|}
\hline Food commodity & Fat, $\%$ & LA, mg/g & ALA, mg/g & DHA, mg/g & o-6 FA, mg/g & $\omega-F A, m g / g$ & TFA,mg/g & $\begin{array}{c}\text { Frequency of } \\
\text { intake }\end{array}$ & $\begin{array}{c}\text { Portion } \\
\text { size, } g\end{array}$ & $\begin{array}{c}\text { Weighted } \\
\text { intake, g/d }\end{array}$ & $\begin{array}{c}\text { o-3 FA, } \\
\text { mg/d }\end{array}$ \\
\hline All sea foods & & & & & & & & & & 19.2 & 252 \\
\hline Fish Bolti & & 4.5 & $\mathbf{0}$ & 5.04 & 4.5 & 13.13 & & & & & \\
\hline Fried Fish & & 50.88 & 2.54 & 0.78 & 50.88 & 3.52 & & & & & \\
\hline Fish Tuna, oven & & 29,93 & 3.9 & 22.4 & 30.36 & 27.11 & & & & & \\
\hline Milouha, Fermented & & 11.09 & $\mathbf{0}$ & 0.9 & 11.09 & 0.9 & & & & & \\
\hline \multicolumn{12}{|l|}{ Dairy products } \\
\hline Milk & 3.5 & 0.707 & 0.336 & & 0.707 & 0.336 & 1.841 & & & 31.5 & 10.584 \\
\hline Cheese hard, gouda & 27.44 & $\mathbf{0}$ & $\mathbf{0}$ & $\mathbf{0}$ & 0 & $\mathbf{0}$ & 16.77 & & & 5 & \\
\hline Cheese soft, white & 10 & 2.02 & 0.96 & $\mathbf{0}$ & 2.02 & 0.96 & 5.26 & & & 45 & 43.2 \\
\hline Yoghurt & 3.5 & 0.703 & $\mathbf{0}$ & $\mathbf{0}$ & 1.41 & & 0.553 & & & 14 & \\
\hline Eggs & 10.1 & 11.41 & 0.41 & 0.73 & 13.85 & 1.14 & $\mathbf{0}$ & & 62 & 17 & 19.38 \\
\hline \multicolumn{12}{|l|}{ Fats and oils } \\
\hline Butter & 74.85 & 20.2 & 9.6 & & 20.6 & 9.6 & 52.6 & & & 10 & 9.6 \\
\hline Fat, bovine & & $\mathbf{0}$ & $\mathbf{0}$ & $\mathbf{0}$ & $\mathbf{0}$ & $\mathbf{0}$ & 6.43 & & & & \\
\hline Fat, camel & & 2.77 & $\mathbf{0}$ & 0 & 2.87 & $\mathbf{0}$ & 2.57 & & & & \\
\hline Olive oil, virgin & 87.1 & 11.55 & 0.47 & $\mathbf{0}$ & 11.55 & 0.47 & $\mathbf{0}$ & & & & \\
\hline Palm oil & 91.2 & 102.1 & 2.41 & $\mathbf{0}$ & 102.1 & 2.41 & 0.21 & & 8.8 & & \\
\hline Sunflower & 94.7 & 69.58 & 0.22 & 0 & & & $\mathbf{0}$ & & & & \\
\hline Sesame butter, Tehina & 58.9 & 243.26 & 9.012 & $\mathbf{0}$ & 252.86 & 9.012 & $\mathbf{0}$ & & & & \\
\hline \multicolumn{12}{|l|}{ Animal proteins } \\
\hline Chicken & 13.31 & 28.8 & 1.4 & 0.3 & 29.6 & 1.8 & & & & 20 & 36 \\
\hline Beef cooked & 2.45 & 1.82 & 0.61 & 0.08 & 2 & 0.78 & $\mathbf{0}$ & & & 22.8 & 17.784 \\
\hline All Foods & & & & & & & & & & & 388.548 \\
\hline
\end{tabular}




\section{Estimated daily Intake of Fat and Essential FA by the Lactating Mothers}

Table 4 presents the contribution of the major food groups to daily fat and omega-3 FA intakes and all women in the study were consuming omnivorous diet. Fish intake in Egypt constitutes $27 \%$ of total meat consumption and estimated daily intake of fishes averaged $20 \mathrm{~g}$, equivalent to $140 \mathrm{~g} / \mathrm{wk}$. Figure (5) illustrates the major sea foods contributing to the diet of the lactating women; tilapia (Bolti fish) contributes to $90 \%$ of all sea foods. Fried tilapia (as eaten) contains $8.9 \%$ total lipid; EPA (C20:5-@3) account for $8.09 \mathrm{wt} \%$ and DHA (C22:6- -3 ) for 5.04 wt $\%$ of total FAs [40]. Accordingly, fish provided weekly $163.6 \mathrm{mg}$ of preformed omega -3 LCPUFA equivalent to $23 \mathrm{mg}$ daily, which is roughly one tenth the recommended daily intake of $200-300 \mathrm{mg}$ DHA for pregnant and lactating mothers. The weighted estimated daily intake was $388 \mathrm{mg}$ (Table 4) from all food sources, including other animal sources such as dairy products, eggs, chicken \& meats and animal fats \& oils. The $\%$ fat content of the oils when multiplied with the respective intake an estimate of 30 grams of total fats (as triglyceride) per subject per day was obtained (Table 4) and this visible oils and fats made up approximately $43 \%$ of the total fat intake of 69.7 grams reported for the Egyptian diet. The dietary pattern demonstrates a disproportionate ratio of omega- 6: omega -3 due to the prominent place of oilseeds rich in the LA [18:2ø-6] in the Egyptian kitchen. Today, the tropical palm oil is the major contributor to visible fat accounting for $38.8 \%$ of total vegetable oils, followed by sunflower $(17.5 \%)$, cottonseed oil (12.2) soybeans (10.4\%), butter ghee $(10.6 \%)$ and animal fats (5\%) (Egyptian chamber of the food industry, 1999). The intakes of SFA, LA and trans FAs, are increased with concomitant reduced intakes of Ф-3 FA. It is evident that dietary trans FAs [TFA; C18:1 trans] are increasing with concomitant reduced intakes of ๑-3 FA.

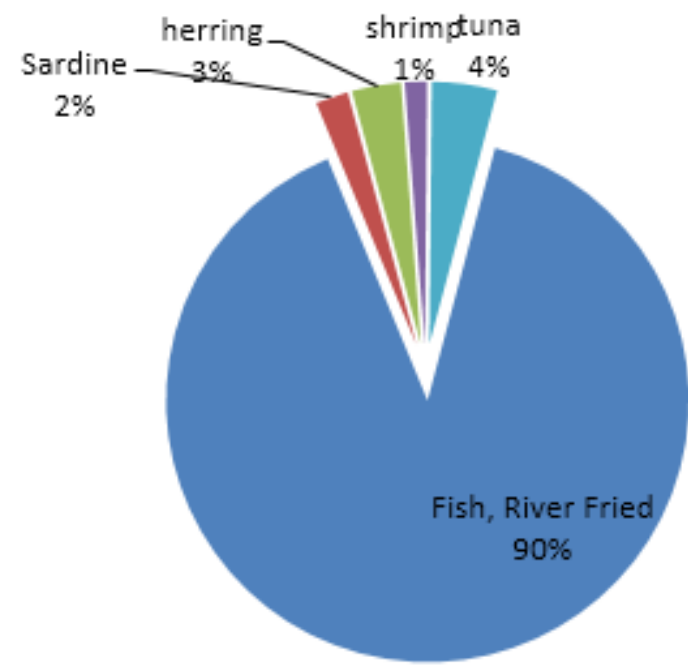

Figure 5. The percentage contribution of different sea foods in the diet of the participating lactating mothers

\section{Discussion}

The Gas chromatography separated 21 FA with chain lengths between $\mathrm{C} 12$ and $\mathrm{C} 24$ in the milk of our lactating mothers with full term and preterm babies; while other studies reported the concentration of 32 FAs from Spanish lactating mothers [49]. The total saturated FA concentration found in the present study is higher [49.3\%] than reported concentrations of $40.7 \%$ from Spain [49]; $41.9 \%$ from the US [38]; 41.9 from Brazil [50]; $46 \%$ from Bolivia [43]; 46.4\% from Australia [51]. It is interesting to note that saturated FA (Lauric and myristic acids) were higher among our lactating mothers than the respective \% values in the milks of a global sample representing 9 countries [35] because saturated FA up to C14:0) are synthesized in the human milk [52]. Palmitic acid (C16:0) concentration was also high (22.5- $27.9 \mathrm{wt} \%)$ and this FA can also be potentially synthesized with high efficiency (74\%) by de novo synthesis from starch particularly under conditions of low dietary fat intake [53]. In this regard, palmitic acid absorption in human milk was reported to be quite high among term and preterm infants, because it is esterified at the $s n-2$ position of the triglycerides [49]. The proportion of the milk MUFA oleic acid average $28.8 \%$. High respective \% of (38.8\%) was reported in the milk of Spanish lactating women [49], due to the high estimated daily intake of $29-32 \mathrm{~g}$ of olive oil, per adult. High oleic acid in the human milk has the advantage that it reduces the melting point of TGs, and provides the liquidity required for the formation, transport and metabolism of milk fat globules [54].

The average concentration of $16.7 \%$ for linoleic acid in the milks of our lactating mothers is in agreement with $16.1 \mathrm{wt} \%$ reported in Spain [49] and $18.9 \pm 5.1 \mathrm{wt} \%$ reported in the US [43]; $12.6-17.3 \mathrm{wt} \%$ from Slovania [55], $22 \mathrm{wt} \%$ from Taiwan [56] and $27.5 \pm 17.4$ from Israel[57]. Low milk LA averaging 9.17 wt \% were reported only in mature milk of lactating mothers from Finland [58]. Between 1944 and 1990, LA concentration has increased from 6 to $15 \mathrm{wt} \%$ in the milk of lactating American women [59], reflecting a secular increase of dietary consumption of LA with seed and vegetable oils. Low alpha linoleic acid concentration similar to that found in the present study $(0.44-0.57 \% \mathrm{FA})$ was reported earlier averaging $0.46 \pm 0.72 \%$ in the milk samples of Israeli lactating women [57]. Higher milk ALA concentration ranging between $0.7-1.3$ wt \% were reported in Spanish lactating mothers [49], which overlap with the recommended concentration ranging between $0.5-1$ wt \% [54].

The high disproportionate LA / ALA ratios found in the present study are almost consistent with the mean ratio of 34.0 reported earlier [38]. Higher ratio of 57.8 (27.5/ 0.46) was reported in Israeli [57]. Respective lower mean ratios of 5.16 (9.17/1.95) was reported in the milk of Finish [58]; $12.7(23.2 / 1.8)$ in milk of Taiwanese [56]. Acceptable LA 
to ALA ratios of 5-10: 1 [31] had been recommended. According to another report, the LA: ALA ratio of 1:1, the rate of DHA biosynthesis is optimum and the conversion rate is reduced at LA: ALA of $4: 1$ and is fully blocked when the ratio was 7:1 [60]. The mean PUFA: SFA of 0.39 obtained in the present study is quite overlapping with the respective ratios of $0.32-0.35$ reported in Germany [61]; while higher ratio of 0.6 was reported in Africa [62]. The milk AA concentrations of $0.44-0.69$ obtained in the present study are overlapping with the worldwide average (WWA) of $0.47 \pm 0.22 \%$ [29]. Higher AA concentration of $0.8 \mathrm{wt} \%$ was reported in the milk of Iranian [63] and of $0.85 \pm 1.24$ in the milk of Israeli lactating women [57]. On the other hand, the milk DHA concentrations of 0.22 $0.24 \%$ FA is lower than the WWA of $0.32 \%$ FA [27]. The lowest breast-milk DHA values fluctuated between 0.06 up to 0.14 wt \% were reported among Canadian, Dutch, French, Pakistani and rural South African lactating mothers [29]. Low DHA concentration of $0.16 \pm 0.09$ wt $\%$ was reported in the milk of American lactating women from Cincinnati [43]; 0.18 wt \% in China [64]; 0.19 wt \% in Hungary [65], and $0.26 \mathrm{wt} \%$ in Mexico [35]. No DHA could be detected in the FA pattern of milk collected from Israeli lactating women [57]. High concentrations of milk DHA was reported among Tanazian lactating mothers $(0.75 \mathrm{~mol} \mathrm{wt} \%)$ with life-long consumption of fish from nearby Lake Kitangiri; Japanese lactating mothers (0.99 and $1.1 \mathrm{wt} \%$ ) [29] and Bolivian forage horticulturist lactating mothers $(0.69 \pm 0.26 \mathrm{wt} \%)$ [43]. A recent study showed no significant differences between the preterm and term milks collected at any stage of lactation from Swiss mothers in the concentrations of AA, DHA and EPA [66]. The Swiss findings (Table 2) disagree with the present results, which showed that milks collected from mothers giving birth preterm babies were $38.8 \%$ higher (Figure 2) in the concentrations of the six intermediate metabolites of essential FA (2.22 wt \%) compared with the respective mean figure of $1.39 \mathrm{wt} \%$ obtained among those giving full term babies. The majority of the milk samples collected from French and Spanish lactating women did not reach the optimal ALA and DHA levels recommended by ESPGAN [67]. The average AA / DHA ratio of $1.8 \pm 0.67$ and $3.1 \pm 2$ in the milks of our lactating mothers with term and preterm infants are much higher than the normal range of $0.5-1$ [67]. High ALA/ DHA ratio of 3.1 was also reported in China and 1.6 in Sweden (Xiang et al., 2005). The sum of the omega -3 LCPUFA EPA+ DHA accounted for 0.39 and $0.37 \mathrm{wt} \%$ in the milks of mothers with term and preterm infants; respectively which are lower than the respective recommended FAO ratios of 0.625 and 0.68 [31]. Long-term 6 months of lactation provides preterm babies with 1.5 times AA $(p<0.05)$ and two times DHA $(p<0.01)$ relative supply than in term milk, which also benefits the development of a preterm infant [70].

Some European countries are trying to ban the import and use of palm oil by their populations due to its high contents of the saturated lauric and stearic fatty acids, which have negative impacts on diverse physiological processes in the human body. Furthermore, the presence of TFAs in the diet of the pregnant and lactating mothers has detrimental effects on the embryo and in infancy and TFA should be as low as possible within the context of a nutritionally adequate diet [72]. Trans fats naturally exist in small amounts in the fat in meat and milk [71]. The TFA concentration averaged 2.59 (1.49-3.34 wt \%) in the milks of Polish lactating mothers at 5-6 week of lactation, whereby, bakery products and snacks were the major contributors [74]. The trans octadecenoic and trans octadecadienoic acids concentrations in the milk of German lactating mothers at the 6th week of lactation showed very high inverse correlation with DHA $(r=-0.51$ and $-0.33, P<0.0001)$ [75]. The upper permissible limit of TFA is $3.0 \%$ per total FAs in human milk not exceeding $0.21 \%$ of dietary energy [73].

The breast fed infant will have sufficient $₫$-6 FAs up to 8 - 12 months of age and sufficient $₫$-3 EFA from human milk for the first 6 months of life if the milk volume is $800-1000 \mathrm{ml} / \mathrm{d}$ and the fat content is $3-4 \mathrm{~g} / \mathrm{dl}, \omega-3 \mathrm{FA}$ supply $\geq 0.5 \%$ of energy and LA to ALA ratio is $4-10: 1[34$, 45]. In malnourished lactating mothers, total milk volume may be reduced as well as milk fat content and essential Ф-3 FA content to be below accepted levels at an earlier age. Results are available for a small number of interventional trials assessing the effect of maternal DHA intake during pregnancy on visual and neuro-developmental outcomes [46]. LC-PUFA $\omega-3$ concentrations in breast milk are sensitive to the consumption of EPA and DHA- rich marine foods, such as ocean fish, salmon and mackerel $[47,48]$.

Nutrition experts recommend that $\omega-3$ FA should be obtained by consumption of foods rich in $₫-3 \mathrm{FA}$ as part of a balanced diet rather than from supplementation. The supply of two servings of fish per week $(200-300 \mathrm{~g})$ equivalent to $300 \mathrm{mg}$ DHA daily had been advocated by the International agencies [32-37]. According to one study, direct consumption of EPA and DHA- rich marine foods, such as ocean fish, salmon and mackerel is considered the best approach to promote LC-PUFA breast milk [47]. Pregnant women receiving two portions of farmed salmon providing $3.45 \mathrm{~g}$ LCPUFA@-3 / per week from $20 \mathrm{wk}$ of pregnancy until delivery had on the $5^{\text {th }}$ lactation day in their breast milk higher proportions of EPA $(80 \%)$, DPA $(30 \%)$, and DHA $(90 \%)$ compared with controls $(P<0.01)$ and a lower LCPUFAœ-6 / Ф-3 ratio[76]. A number of reports associate higher cognitive, stereoacuity, or visual acuity in children at 3.5 years of age to higher maternal seafood intake during pregnancy [46]. On the other hand, although Brazilian nursing women consume $2 \mathrm{~kg}$ fried sardines every 15 days to supply daily approximately 80 grams containing $5.2 \mathrm{wt} \%$ DHA and 
total omega-3 FA of $9.8 \mathrm{wt} \%$, the DHA concentration didn't increase significantly in their breast milk [77].

The extent to which aquaculture may influence LCPUFAø-3 intake depends on whether increased availability of fish would generate an increased demand. Major changes in acceptance of fish will be needed if the suggested recommended intakes of 1-2 servings/wk fish are to be met. There are needs to develop technologies that are both economical and sustainable for the production of deodorized and stabilized oils derived from inedible ( $₫-3)$ PUFA-rich marine organisms (e.g., menhaden) to be incorporated in a wide variety of fortified foods. Other investigators consider the strategy of increasing the $\omega-3 \mathrm{FA}$ status of individuals brought about by consuming fish or fish oils, is unsustainable globally.

Fortified foods and fish oil supplements are large market growth areas by commercial sales figures; however, there are no reliable data indicating the amounts of EPA and DHA contribute to the pregnant and lactating women diets. The children of Australian pregnant women who consumed from 20 weeks' gestation until delivery fish oil supplement contained $2.2 \mathrm{~g}$ DHA and $1.1 \mathrm{~g}$ EPA /day, attained a significantly higher score for eye and hand coordination than those in the placebo group [78]. According to another study, the routine supplementation with DHA-containing supplement was not adequate to raise mother's milk levels to the WWA [28]. Theoretical concerns remain the potential detrimental effects of selective $\omega-3$ PUFA supplementation, which could lead to a reduction in the essential $₫-6$ arachidonic FA status at high doses and more studies are needed to confirm beneficial rather than harmful effects on development.

Most of the reported RCT have been performed with DHA and AA intakes in the current Western human milk range, which might not be applicable under the situation prevailing in Egypt. The breast milk of women in Egypt is markedly different to the typical breast milk composition in Western countries reflecting different dietary habits and dietary patterns by the different ethnic groups. Randomized controlled trials (RCT) are needed to assess the effectiveness of supplementing lactating women with fish rich in preformed DHA on the milk FA concentration and on the well-being of the nursing infant, with focus on preterm infants, who are at high-risk vulnerable group due to their unique biological suboptimal early exposures.

\section{Conclusions}

The present work is a cross-sectional study and the sample size in this study is a limitation issue. However, based on $80 \%$ statistical power and a significance level of 0.05 , the sample size allowed detecting a difference in DHA concentrations of $0.05 \%$. Milk AA and DHA concentrations in mothers giving birth to term babies are below that the respective worldwide average and the DHA concentrations increased significantly, as lactation progressed, denoting the significance for campaign to prolong the duration of breast feeding in Egypt and in the other Middle Eastern and the north Africa area. The milk FA concentration of mothers of preterm babies \% had some unique biological characteristics, with significant higher content $(\mathrm{P}<0.05)$ of intermediary metabolites of essential FA $(2.2 \mathrm{wt} \%)$ at all stages of lactation compared with mature milks (1.4 wt \%). However, the milk DHA was below worldwide average and the diet of their lactating mothers did not supply the minimum daily requirement. Country specific human milk nutrient information is the first step to create scientific based evidences and the foundation for the management of infant feeding before planning supplementation strategies to combat deficiencies in essential FAs.

\section{Acknowledgements}

The authors would like to thank the families who generously participated in the Trial, the Investigative Team and research staff. We dedicate this publication to the memory of our coauthors, beloved scientists, teachers and friends, and Peter Furst, who contributed to the science of nutrition research.

\section{Conflict of Interest}

None of the authors has conflict of interest

Grants and support MAM is supported by National research center MSc Postgraduate support.

\section{Abbreviations}

ALA or $\alpha$-LA = Alpha linolenic acid; $\mathrm{AA}=$ Arachidonic acid;

$\mathrm{AI}=$ Adequate intake;

$\mathrm{BMI}=$ Body mass index;

$\mathrm{BHT}=$ butylhydroxytoluene;

DHA = Docosahexanoic acid;

$\mathrm{DNL}=$ De novo lipogenesis;

$\mathrm{EPA}=$ Eicosapentanoic acid;

FA $=$ Fatty acid;

FADS1 $1 / 2=$ Fatty acid desaturase genes 1 and 2;

FAME $=$ Fatty acid methyl ester;

$\mathrm{FFQ}=1$ food frequency questionnaire;

$\gamma \mathrm{LA}=$ gamma-linolenic acid;

$\mathrm{HAZ}=$ Height for age $\mathrm{Z}$ score;

LA = Linoleic acid;

LCPUFA = Long chain polyunsaturated fatty acid;

LCSAFA = long chain saturated-FA;

MCSFA = Medium chain saturated fatty acid;

MUFA = Mono-unsaturated fatty acid;

$\omega 3=$ Omega- $3 ; \omega 6=$ Omega -6 ; 
PUFA $=$ Polyunsaturated fatty acids;

$\mathrm{RCT}=$ randomized clinical trial;

$\mathrm{SCD}=$ stearoyl-CoA desaturase;

SFA saturated fatty acid;

TFA $=$ Trans fatty acid;

$\mathrm{TG}=$ Triglyceride;

$\mathrm{WAZ}=$ Weight for age $\mathrm{Z}$-score;

WHZ $=$ Weight for height $Z$-score;

$\mathrm{WWA}=$ World wide average .

\section{REFERENCES}

[1] Ballard, O. and A.L. Morrow, Human milk composition: nutrients and bioactive factors. Pediatr Clin North Am, 2013. 60(1): 49-74.

[2] Victora, C.G., et al., Breastfeeding in the 21st century: epidemiology, mechanisms, and lifelong effect. Lancet, 2016:(10017): 475-490.

[3] Mohammad MA, Haymond MW The magic of mother's milk. Diabetes, 2012. 61(12): 3076-7.

[4] Mohammad MA, Sunehag AL, Haymond MW Effect of dietary macronutrient composition under moderate hypocaloric intake on maternal adaptation during lactation. Am J Clin Nutr, 2009. 89(6): 1821-1827.

[5] Mohammad MA, Haymond MW Regulation of lipid synthesis genes and milk fat production in human mammary epithelial cells during secretory activation. Am J Physiol Endocrinol Metab, 2013. 305(6): E700-716.

[6] Manson WG, Weaver LT Fat digestion in the neonate. Arch Dis Child Fetal Neonatal Ed, 1997. 76(3): F206-211.

[7] Holman RT, Johnson SB, Hatch TF A case of human linolenic acid deficiency involving neurological abnormalities. Am J Clin Nutr, 1982. 35(3): p. 617-623.

[8] Bourre JM, et al., Control of brain fatty acids. Ups J Med Sci Suppl, 1990. 48: 109-131.

[9] Bourre JM, et al., Brain cell and tissue recovery in rats made deficient in $\mathrm{n} 3$-fatty acids by alteration of dietary fat. J Nutr, 1989. 119(1): 15-22.

[10] Bourre JM, et al., The effects of dietary alpha-linolenic acid on the composition of nerve membranes, enzymatic activity, amplitude of electrophysiological parameters, resistance to poisons and performance of learning tasks in rats. J Nutr, 1989. 119(12): 1880-1892.

[11] Koletzko B, Mrotzek M, Bremer HJ, Fatty acid composition of mature human milk in Germany. Am J Clin Nutr, 1988. 47(6): 954-959.

[12] Uauy R, Hoffman DR Essential fatty acid requirements for normal eye and brain development. Semin Perinatol, 1991. 15(6): 449-455.

[13] Makrides $M$ et al., Neurodevelopmental outcomes of preterm infants fed high-dose docosahexaenoic acid: a randomized controlled trial. JAMA, 2009. 301(2): 175-182.
[14] Blencowe H., et al., National, regional, and worldwide estimates of preterm birth rates in the year 2010 with time trends since 1990 for selected countries: a systematic analysis and implications. Lancet, 20 :(9832)379 .12: 2162-2172.

[15] Kannan S., et al., Exposures to airborne particulate matter and adverse perinatal outcomes: a biologically plausible mechanistic framework for exploring potential effect modification by nutrition. Environ Health Perspect 2: 1636-1642.

[16] Gawrisch K, Soubias O, Mihailescu M, Insights from biophysical studies on the role of polyunsaturated fatty acids for function of G-protein coupled membrane receptors. Prostaglandins Leukot Essent Fatty Acids, 2008. 7:(5-3)9. 131-134.

[17] Shaikh SR, Jolly CA, Chapkin RS. n-3 Polyunsaturated fatty acids exert immunomodulatory effects on lymphocytes by targeting plasma membrane molecular organization. Mol Aspects Med, 2012. 33(1): 46-54.

[18] Kuipers RS et al., Fetal intrauterine whole body linoleic, arachidonic and docosahexaenoic acid contents and accretion rates. Prostaglandins Leukot Essent Fatty Acids, 2012. 86(1-2): 13-20.

[19] Lauritzen L., et al., The essentiality of long chain n-3 fatty acids in relation to development and function of the brain and retina. Prog Lipid Res, 2001. 40(1-2): 1-94.

[20] Cunnane SC, et al., Breast-fed infants achieve a higher rate of brain and whole body docosahexaenoate accumulation than formula-fed infants not consuming dietary docosahexaenoate. Lipids, 2000. 35(1): 105-111.

[21] Alessandri JM, et al., Polyunsaturated fatty acids in the central nervous system: evolution of concepts and nutritional implications throughout life. Reprod Nutr Dev, 2004. 44(6) 509-538.

[22] Ailhaud G, et al., Temporal changes in dietary fats: role of ๑-6 polyunsaturated fatty acids in excessive adipose tissue development and relationship to obesity. Prog Lipid Res, 2006. 45(3): 203-236.

[23] Innis SM. Perinatal biochemistry and physiology of long-chain polyunsaturated fatty acids. J Pediatr, 2003. 143(4 Suppl): S1-8.

[24] Guesnet P, Alessandri JM. Docosahexaenoic acid (DHA) and the developing central nervous system (CNS) Implications for dietary recommendations. Biochimie, 2011. 93(1): 7-12.

[25] Lassek WD, Gaulin SJ. Linoleic and docosahexaenoic acids in human milk have opposite relationships with cognitive test performance in a sample of 28 countries. Prostaglandins Leukot Essent Fatty Acids, 20:(5)91. 195-201.

[26] Rapoport SI, Rao JS, Igarashi M. Brain metabolism of nutritionally essential polyunsaturated fatty acids depends on both the diet and the liver. Prostaglandins Leukot Essent Fatty Acids, 2007. 77(5-6): 251-261.

[27] Domenichiello AF, et al., The effect of linoleic acid on the whole body synthesis rates of polyunsaturated fatty acids from alpha-linolenic acid and linoleic acid in free-living rats. J Nutr Biochem, 2016. 30: 167-176. 
[28] Juber BA, et al., Breast milk DHA levels may increase after informing women: a community-based cohort study from South Dakota USA. Int Breastfeed J, 2016. 12: 7.

[29] Brenna JT et al., Docosahexaenoic and arachidonic acid concentrations in human breast milk worldwide. Am J Clin Nutr, 2007. 85(6): 1457-1464.

[30] Smith SL, Rouse CA Docosahexaenoic acid and the preterm infant. Matern Health Neonatol Perinatol, 2017. 3: 22.

[31] FAO/WHO, Lipids in early development. In: Fats and oils in human nutrition. Report of a Joint Expert Consultation FAO/WHO, Rome, 1994: 49-55.

[32] Smit EN et al., Estimated biological variation of the mature human milk fatty acid composition. Prostaglandins Leukot Essent Fatty Acids, 2002. 66(5-6): 549-555.

[33] Fokkema MR et al ,.Polyunsaturated fatty acid status of Dutch vegans and omnivores. Prostaglandins Leukot Essent Fatty Acids, 2000. 63(5): 279-285.

[34] Brenna JT, Lapillonne A. Background paper on fat and fatty acid requirements during pregnancy and lactation. Ann Nutr Metab, 2009. 55(1-3): 97-122.

[35] Yuhas R, Pramuk K, Lien EL Human milk fatty acid composition from nine countries varies most in DHA. Lipids, 2006. 41(9): p. 851-858.

[36] Uauy R, Dangour AD. Fat and fatty acid requirements and recommendations for infants of 0-2 years and children of 2-18 years. Ann Nutr Metab, 2009. 55(1-3): 76-96.

[37] Innis SM. Fatty acids and early human development. Early Hum Dev, 2007. 83(12): 761-766.

[38] Borschel MW. et al., Fatty acid composition of mature human milk of Egyptian and American women. Am J Clin Nutr, 1986. 44(3): 330-335.

[39] Gibson RA, Kneebone GM. Effect of sampling on fatty acid composition of human colostrum. J Nutr, 1980. 110(8): 1671-1675.

[40] Hussein LA, Ali M, Abouelhassan M, Grzeskiewicz A, Cantellops S. Assessment of the fatty acid patterns in vegetable oils, fats and fat-rich foods commonly consumed in Egypt. Grasas y Aceites 2001. 52: 163-170.

[41] Folch J, Lees M, Sloane Stanley GH, A simple method for the isolation and purification of total lipides from animal tissues. J Biol Chem, 1957. 226(1): 497-509.

[42] Lepage G, Roy CC. Direct transesterification of all classes of lipids in a one-step reaction. J Lipid Res, 1986. 27(1): $114.20-$

[43] Martin MA et al., Fatty acid composition in the mature milk of Bolivian forager-horticulturalists: controlled comparisons with a US sample. Matern Child Nutr, 2012. 8(3): 404-418.

[44] Sosenko IR, Do polyunsaturated fatty acids protect against oxidant-induced lung damage? J Nutr, 1995. 125(6 Suppl): 652S-1656S.

[45] Bzikowska-Jura A, et al., The Concentration of Omega-3 Fatty Acids in Human Milk Is Related to Their Habitual but Not Current Intake. Nutrients, 2019. 11.(7)
[46] Braarud HC, et al., Maternal DHA Status during pregnancy has a positive impact on infant problem solving: A Norwegian prospective observation study. Nutrients, 2018. 10.(5)

[47] Olafsdottir AS, et al., Polyunsaturated fatty acids in the diet and breast milk of lactating icelandic women with traditional fish and cod liver oil consumption. Ann Nutr Metab, 2006. 50(3): 270-276.

[48] Weaver BJ, Holob BJ. Health effects and metabolism of dietary eicosapentaenoic acid. Prog Food Nutr Sci, 1988. 12(2): 1550-1551

[49] Lopez-Lopez A, et al., Fatty acid and sn-2 fatty acid composition in human milk from Granada (Spain) and in infant formulas. Eur J Clin Nutr, 2002. 56(12): 1242-1254.

[50] Da Cunha J, Macedo da Costa TH, Ito MK Influences of maternal dietary intake and suckling on breast milk lipid and fatty acid composition in low-income women from Brasilia, Brazil. Early Hum Dev, 2005. 81(3): 303-311.

[51] Makrides $M$ et al., Changes in the polyunsaturated fatty acids of breast milk from mothers of full-term infants over 30 wk of lactation. Am J Clin Nutr, 1995. 61(6): 1231-1233.

[52] Lucas A et al., How much energy does the breast fed infant consume and expend? Br Med J (Clin Res Ed), 1987. 295(6590): 75-77.

[53] Prentice AM, Prentice A. Energy costs of lactation. Annu Rev Nutr, 1988. 8: p. 63-79.

[54] Jensen, R.G., Lipids in human milk. Lipids, 1999. 34(12): 1243-1271.

[55] Fidler N, Salobir K, Stibilj V.Fatty acid composition of human milk in different regions of Slovenia .Ann Nutr Metab, 2000. 44(5-6): 187-193.

[56] Wu TC, et al., Fatty acid composition of Taiwanese human milk. J Chin Med Assoc, 2010. 73(11): 581-588.

[57] Lubetzky R, et al., Human milk fatty acids profile changes during prolonged lactation: a cross-sectional study. Isr Med Assoc J, 2012. 14(1): 7-10.

[58] Laiho $\mathrm{K}$, et al., Breast milk fatty acids, eicosanoids, and cytokines in mothers with and without allergic disease. Pediatr Res, 2003. 53(4): 642-647.

[59] Gibson RA, Muhlhausler B, Makrides M. Conversion of linoleic acid and alpha-linolenic acid to long-chain polyunsaturated fatty acids (LCPUFAs), with a focus on pregnancy, lactation and the first 2 years of life. Matern Child Nutr, 2011. 7 Suppl 2: 17-26.

[60] Burdge GC,Wootton SA. Conversion of alpha-linolenic acid to eicosapentaenoic, docosapentaenoic and docosahexaenoic acids in young women. Br J Nutr, 2002. 88(4): 411-420.

[61] Koletzko B, Thiel I, Abiodun PO. The fatty acid composition of human milk in Europe and Africa. J Pediatr, 1992. 120(4 Pt 2): S62-70.

[62] Koletzko B, Thiel I, Abiodun PO. Fatty acid composition of mature human milk in Nigeria. Z Ernahrungswiss, 1991. 30(4): 289-97. 
[63] Kelishadi R. et al., A study on lipid content and fatty acid of breast milk and its association with mother's diet composition. J Res Med Sci, 2012. 17(9): 824-827.

[64] Xiang M, Harbige LS, Zetterstrom R. Long-chain polyunsaturated fatty acids in Chinese and Swedish mothers: diet, breast milk and infant growth. Acta Paediatr, 2005. 94(11): 1543-1549.

[65] Minda H, et al., Changes of fatty acid composition of human milk during the first month of lactation: a day-to-day approach in the first week. Ann Nutr Metab, 2004. 48(3): 202-209.

[66] Thakkar SK, et al., Temporal Progression of Fatty Acids in Preterm and Term Human Milk of Mothers from Switzerland. Nutrients, 2019. 11.(1)

[67] Fave G, et al., Nutritional quality of human milk from Mediterranean lactating women: a preliminary approach towards personalised nutrition. Genes Nutr, 2007. 2(1): 95-98.

[68] Genzel-Boroviczeny O, Wahle J, Koletzko B. Fatty acid composition of human milk during the 1st month after term and preterm delivery. Eur J Pediatr, 1997. 156(2): 142-147.

[69] Marosvolgyi T, et al., [Fatty acid composition of human milk in mothers of preterm and full-term infants in the first three weeks of lactation]. Orv Hetil, 2006. 147(31): 1459-1463.

[70] Luukkainen P, Salo MK, Nikkari T. Changes in the fatty acid composition of preterm and term human milk from 1 week to 6 months of lactation. J Pediatr Gastroenterol Nutr, 1994. 18(3): 355-360.

[71] Brownell KD, Pomeranz JL. The trans-fat ban--food regulation and long-term health. N Engl J Med, 2014. 370(19): 1773-1775.

[72] Specht IO, et al., The influence of prenatal exposure to trans-fatty acids for development of childhood haematopoietic neoplasms (EnTrance): a natural societal experiment and a case-control study. Nutr J, 2018. 17(1): 13.

[73] Mozaffarian D, Aro A, Willett WC. Health effects of trans-fatty acids: experimental and observational evidence. Eur J Clin Nutr, 2009. 63 Suppl 2: S5-21.

[74] Mojska H, et al., Trans fatty acids in human milk in Poland and their association with breastfeeding mothers' diets. Acta Paediatr, 2003. 92(12): 1381-1387.

[75] Szabo E, et al., Trans Octadecenoic acid and trans octadecadienoic acid are inversely related to long-chain polyunsaturates in human milk: results of a large birth cohort study. Am J Clin Nutr, 2007. 85(5): 1320-1326.

[76] Urwin HJ, et al., Salmon consumption during pregnancy alters fatty acid composition and secretory IgA concentration in human breast milk. J Nutr, 2012. 142(8): $1603-1610$.

[77] Patin RV, et al., The influence of sardine consumption on the omega-3 fatty acid content of mature human milk. J Pediatr (Rio J), 2006. 82(1): 63-69.

[78] Dunstan JA, et al., Cognitive assessment of children at age $2(1 / 2)$ years after maternal fish oil supplementation in pregnancy :a randomised controlled trial. Arch Dis Child Fetal Neonatal Ed, 2008. 93(1): F45-50. 